\title{
Relationship between perceived social support and postpartum care attendance in three Latin American countries: a cross- sectional analytic study
}

Nancy R. Cardona Cordero ${ }^{1}$, José Perez Ramos', Zahira Quiñones Tavarez², Scott Mclntosh'1, Esteban Avendaño³, Carmen DiMare ${ }^{3}$, Deborah J. Ossip ${ }^{1}$ and Timothy De Ver Dye ${ }^{1 *}$ (D)

\begin{abstract}
Background: Postpartum Care is a strategy to improve survival of women and newborns, especially in low- and middle-income countries. Early post-partum care can promote healthy behaviors and the identification of risk factors associated with poorer pregnancy-related outcomes. The objective of this study was to assess the association of perceived social support with attendance to post-partum care in women from three Latin-American and Caribbean countries: Costa Rica, Dominican Republic and Honduras.

Methods: Women aged 18+ who completed a pregnancy in the past 5 years were interviewed in local healthcare and community settings in each country. Perceived social support (PSS) was the primary explanatory variable and the primary outcome was self-reported attendance to post-partum care. Odds Ratios (OR) with 95\% confidence intervals derived from logistic regression documented the association between variables. Adjusted Odds Ratios (AOR) were calculated, controlling for social and pregnancy-related confounders. Hosmer- Lemeshow's Goodnessof-Fit statistic was computed to assess model fit.

Results: Our cohort of 1199 women across the three Latin-American and Caribbean countries showed relatively high attendance to post-partum care $(82.6 \%, n=990)$. However, $51.7 \%(n=581)$ of women reported lower levels of total PSS. Women were more likely to attend postpartum care if they had mean and higher levels of PSS Family subscale (OR: 1.9, 95\%Cl: 1.4, 2.7), Friends subscale (OR 1.3, 95\%Cl: 0.9,1.8), Significant Other subscale (OR 1.8, 95\%Cl: $1.3,2.4)$ and the Total PSS (OR 1.8, 95\%Cl: 1.3, 2.5). All associations were statistically significant at $p<0.05$, with exception of the Friends subscale. Women with higher levels of total PSS were more likely to attend to post-partum care (AOR:1.40, 0.97, 1.92) even after controlling for confounders (education, country, and food insecurity).

Conclusions: Women with higher perceived social support levels were more likely to attend to post-partum care. From all countries, women from Dominican Republic had lower perceived social support levels and this may influence attendance at post-partum care for this subgroup. Societal and geographic factors can act as determinants when evaluating perceived social support during pregnancy.
\end{abstract}

Keywords: Postpartum care, Social support, Maternal health, Latin America, Costa Rica, Dominican Republic, Honduras, Social determinants

\footnotetext{
* Correspondence: Tim_dye@urmc.rochester.edu

'University of Rochester, School of Medicine and Dentistry, Obstetrics and Gynecology Department Research Division, 601 Elmwood Avenue, Rochester, NY 14642, USA

Full list of author information is available at the end of the article
}

(c) The Author(s). 2021, corrected publication 2021. Open Access This article is licensed under a Creative Commons Attribution 4.0 International License, which permits use, sharing, adaptation, distribution and reproduction in any medium or format, as long as you give appropriate credit to the original author(s) and the source, provide a link to the Creative Commons licence, and indicate if changes were made. The images or other third party material in this article are included in the article's Creative Commons licence, unless indicated otherwise in a credit line to the material. If material is not included in the article's Creative Commons licence and your intended use is not permitted by statutory regulation or exceeds the permitted use, you will need to obtain permission directly from the copyright holder. To view a copy of this licence, visit http://creativecommons.org/ licenses/by/4.0/ 


\section{Background}

Women transitioning from the antepartum phase of pregnancy-related care to the postpartum phase face simultaneous challenges that include learning new maternal skills, making reproductive choices, and maintaining their personal and family health. Globally, almost $40 \%$ of women experience complications after delivery and 15\% develop life-threatening problems [1]. Postpartum care (PPC) is a critical time that provides an opportunity to assess and enhance women's physical, social, and psychological health. In low- and middle-income countries, PPC has been a interventional tool to decrease maternal and neonatal morbidity and mortality $[1,2]$.

An essential component of PPC is the postpartum visit, and as many as $40 \%$ of women do not attend follow-up postpartum [3]. In 2014, the World Health Organization recommended that a woman and her child should receive postpartum care $24 \mathrm{~h}$ after delivery and at least three more times. In low income countries, however, between 20 and 35\% of women use any PPC services [2]. Low use of postpartum services is associated with lack of education, poverty, and limited access to health care [4]. In fact, the poorest $20 \%$ of the population in most Latin American and Caribbean (LAC) countries is still lagging behind toward reducing inequalities in reproductive and maternal-child health [5]. Likewise, reproductive and maternal interventions are more inequitable than those delivered to children in LAC [5]. Therefore, attendance to care and risks during the postpartum period may affect populations disproportionally and renewed actions are needed to improve maternal health equity.

Studies have also shown that adaptive maternal behaviors can be influenced by a woman's perceptions of the amount of positive support she is receiving [6]. Greater social support has been linked to better health status and as a mediator for stress during pregnancy [7] and the postpartum period. Social support has been defined as 'an exchange of resources between at least two individuals perceived by the provider or recipient to be intended to enhance the well-being of the recipient.' [8] Perceived social support is an indicator of social support adequacy (e.g., network structure and received support) when compared to the needs and expectations of the individual [9]. Therefore, social support can be defined by structure depending on the relationship with its recipient (family, friends, significant others, professionals) or function (informational, instrumental, emotional, appraisal) [10]. Further, social support may impact a woman's adaptation and transition process and influence her immediate decisions and promote postpartum maternal health.

Social determinants in countries undergoing a rapid health transition such as LAC countries, may affect disproportionally sub-populations in maternal, reproductive, and child health. When evaluating the national composite coverage index stratified by wealth in LAC countries, Costa Rica, Honduras and the Dominican Republic have a similar absolute inequality between the groups. Additionally, evidence suggests that up to 2010 infant mortality has fallen and life expectancy has increased gradually for these countries, but there is no information about the influence that postpartum care may have in maternal health. Prior research has focused on how information and communication technologies (ICT) have influenced maternal health in selected LAC countries [11]. The aim of this study was to determine attendance to postpartum care in areas of three LAC countries: Costa Rica, Honduras and Dominican Republic and to evaluate its relationship with perceived social support and associated factors. Results can serve as a baseline for the scientific community and practitioners where interventions can be implemented and maternal health can be improved for LAC.

\section{Methods \\ Setting and sample}

This cross-sectional study was nested within a larger $\mathrm{NIH}$-funded maternal health research and training initiative (MundoComm; www.mundocomm.org) and evaluated differences in postpartum care attendance, its relationship with perceived social support, and affiliated social, demographic, and pregnancy-related characteristics. To assess these behaviors, a survey was developed and administered to women of rural communities in Costa Rica, Dominican Republic, and Honduras.

\section{Survey development}

The survey was divided into topics including sociodemographics, maternal health, access to information and communication technologies, use of social media, antepartum and postpartum care. Relevant to the current analyses, the survey included an adaptation of validated psychosocial scales including the Multidimensional Scale of Perceived Social Support (PSS) [12]. The survey was developed in English and translated into Spanish, then backtranslated into English using the Brislin method [13]. Several iterations of the survey were pretested individually by each in-country team [14]. Feedback during these processes helped to adapt the survey to become culturallyand linguistically- relevant for the participating countries.

\section{Measures}

Sociodemographic characteristics were assessed from the first section of the survey and transformed into categorical values. Binary categories were created for maternal education, marital status and maternal age, which was based on the mean age for our cohort. Worries about enough food during pregnancy was a four-option question and was transformed into two food insecure 
categories. Country of residence included three categories (Costa Rica, Dominican Republic, and Honduras). Characteristics of pregnancy were acquired from different sections of the survey and transformed into categorical values. Intentions of becoming pregnant in the woman's most recent completed pregnancy were assessed using the CDC Pregnancy Risk Assessment Monitoring System (PRAMS)'s standardized question: "Thinking back to just before you got pregnant with your new baby, how did you feel about becoming pregnant?" [15]. Additional questions included were based on the CDC's Reproductive Health Survey series [16]. Questions include: 1) Before your last pregnancy, were you trying to become pregnant? 2) how many children have you have that live with you and how many children do you have that don't live with you? 3) did you try breastfeed? 4) does your baby came before expected time? 5) did you seek postpartum care on your last pregnancy? Complications during the first 6 weeks of delivery were also assessed and included severe bleeding, bad vaginal smell, infected surgery wounds, fainting, comma, high fever, pain urination, pelvic pain, breast infection, continuous urinary leak, and fecal flow. We used CDC's Health-Related Quality of Life 14 (HRQOL-14) General Health Measure to assess self-described health status [17]. Additionally, a question asked if a health services provider had told the participant that they had a chronic health condition. Both variables were transformed into dichotomous categorical variables. The Multidimensional Score of Perceived Social Support [12] was assessed and divided into three standardized subscales (Family, Friends, Significant Other) and a Total Scale (four items for each sub-score and 12 for the total score). PSS was analyzed several ways: 1 ) as a continuous variable (standardized T-score (mean $=50$; standard deviation $=10)$ [18] and 2) as a dichotomous categorical variable cut at the mean of the raw PSS score, low (8.4 or less) and high (Over 8.4).

\section{Data collection and processing}

Study participants were women age 18 years and older, had at least one pregnancy in the 5 years prior to the study (regardless of outcome), and had to be able to read and verbally consent to participate. A house-to-house approach and snowball sampling methodology was used to recruit participants. Recruitment occurred during the Spring and Summer of 2017 in the province of Heredia in Costa Rica, the department of Olancho in Honduras, and in the province of Santiago in the Dominican Republic.

\section{Data analysis}

All statistical analyses were performed using IBM SPSS statistical software, Version 25 (IBM SPSS Statistics for Windows, Version 27.0. Armonk, NY: IBM Corp). The independent variables in the analysis were country of residence, maternal age, education, marital status, food insecurity, perception of health, health problems, becoming pregnant, first time mother, and premature baby. The dependent variable in these analyses was postpartum care attendance. We used descriptive statistics to examine the relationship and describe population characteristics ( $\mathrm{n}$ and \%). The main explanatory variable was total perceived social support score and respective subscales. We tested the distribution of continuous variables (PSS Total Score and subscales) using the Normality test. PSS values for each subscale and total score were transformed to $\mathrm{z}$-scores and then into standardized $\mathrm{t}$ scores for comparison [18]. The correlation coefficient was calculated for all sub-scales and the PSS Total score was used as the independent variable for further analyses. Analysis of variance (ANOVA) was used to test for differences between participants who attended postpartum care and those who did not by PSS subscale and PSS total score. Correlation between PSS subscales and total score was estimated using Spearman's rank order correlation coefficient (See Supplemental material). Based on these results, we used PSS Total score as the main explanatory variable using high and low (higher than the mean and lower than the mean) categories. To assess the bivariate associations between attendance to postpartum care and PSS total score, we used bivariate logistic regression model. We computed crude Odds Ratios (OR) and 95\% confidence intervals for potential confounders for both primary variables (PPC and PSS) considering demographic, social, health- and pregnancy related variables. We included potential confounders of primary relationship between PPC and PSS in our multivariate model in their $p$-value in both bivariate analyses was $<0.20$ [19]. Potential confounding variables included sociodemographic (age, country of residence, education and food security), health (health problems, perception of health) and pregnancy-related (intended pregnancy, first-time mothers) characteristics. We used forward stepwise selection to add possible confounders and calculated adjusted OR (AOR). Hosmer - Lemeshow's Goodness-of-Fit [19] statistic was computed to assess model fit. Statistical significance for quantitative analyses was determined if $p<0.05$ (two-tailed tests).

\section{Regulatory process and ethical considerations}

Multiple iterations of regulatory documents were assessed and addressed by each institutional review board. The MundoComm project was approved by the Universidad de Ciencias Médicas (UCIMED) FWA Institutional Review Board in Costa Rica and (with local approval) in Honduras (as a proxy, since Honduras did not have an FWA Institutional Review Board). In addition, in the Dominican Republic, the study was reviewed and 
approved by Consejo Nacional de Bioética en Salud (CONABIOS) at the national level and the Pontificia Universidad Católica Madre y Maestra (PUCMM)'s FWA Institutional Review Board at the university level. Regulatory language for each country agency was incorporated in the survey. Additionally, the project was approved by the University of Rochester's Research Subjects Review Board. All data collectors had completed appropriate ethics certification in their country.

\section{Results}

\section{Sample characteristics}

Our cohort consisted of 1199 women across countries (Costa Rica: 401; Dominican Republic: 404; Honduras: 394). Women's age at time of interview was 27.1 years. Women were surveyed, on average, 27 months postpartum (with Honduran women interviewed significantly more recently at 23 months post-partum), and interviews lasted an average of $19 \mathrm{~min}$, with no significant variation by country (data not shown). Demographic and pregnancy-related characteristics of our cohort are presented in Table 1 . The majority of women were married or living as married $75 \%(n=898)$ and less than 10\% $(n=$ $107)$ had attained an educational level higher than high school. Although most women $(n=822,68 \%)$ perceived their health status as good, very good or excellent, $23 \%$ $(n=285)$ reported to have at least one health-related problem. In our study population, $8 \%(n=101)$ of postpartum women to reported have gestational diabetes and $24 \%$ $(n=274)$ reported hypertension. Pregnancy was desired by 497 (41\%) of the women, and $311(26 \%)$ of the women were first-time mothers. In total, $14 \%(n=171)$ of women had delivered at fewer than 37 weeks of pregnancy.

Overall, $82 \%(n=990)$ of women attended to PPC and the majority implemented healthy PPC habits such as breastfeeding ( $n=1126,94 \%)$ (Table 2). In most women ( $n=787,81 \%)$, postpartum care occurred 10 days or less which is consistent with the perception of $83 \%(n=801)$ of women who agreed that attendance should happen in less than 10 days of partum. Women opted for first-level centers $(n=526,53 \%)$ as their main location to receive postpartum care, followed by public $(n=256,25 \%)$ and private $(n=188,19 \%)$ hospitals. Postpartum care services were mostly provided by doctors or doctor's assistants (75\%), followed by nurses. At 6 weeks of postpartum, the most common complications reported were pelvic pain $(n=366,30 \%)$, urination pain $(n=235,19 \%)$, and severe bleeding $(n=185,15 \%)$.

\section{Main findings}

Perceived Social Support (PSS) was evaluated as a standardized scale and as a categorical variable (low vs high) and results are shown in Table 3. Standardized median scores for our cohort varied by subcategory as follows: Standardized PSS scores indicate that women who attended PPC had slightly higher mean levels in all PSS

Table 1 Women's socio-demographic and pregnancy-related characteristics

\begin{tabular}{|c|c|c|c|c|c|}
\hline Demographics \& Health & $\mathbf{N}$ & $\%$ & Pregnancy-related & $\mathbf{N}$ & $\%$ \\
\hline Country & 1199 & & & & \\
\hline Costa Rica & 401 & 33.44 & Becoming Pregnant now & 1186 & \\
\hline Dominican Republic & 404 & 33.69 & Yes & 497 & 41.91 \\
\hline Honduras & 394 & 32.86 & No & 689 & 58.09 \\
\hline Age & 1197 & & First time mother & 1177 & \\
\hline $18-27 y r s$ & 669 & 44.11 & Yes & 311 & 26.42 \\
\hline $28+y r s$ & 528 & 55.89 & No & 866 & 73.58 \\
\hline School & 1161 & & Gestational diabetes & 1195 & \\
\hline High school or less & 1044 & 89.92 & Yes & 101 & 8.45 \\
\hline More than Highschool & 107 & 9.22 & No & 1094 & 91.55 \\
\hline Married or living as married & 1192 & & Hypertension during pregnancy & 1135 & \\
\hline Yes & 898 & 75.34 & Yes & 274 & 24.14 \\
\hline No & 294 & 24.66 & No & 855 & 75.33 \\
\hline Health Problems & 1199 & & Food insecure during pregnancy & 1197 & \\
\hline At least one & 285 & 23.77 & Yes (One or more times) & 549 & 45.86 \\
\hline None & 914 & 76.23 & No & 648 & 54.14 \\
\hline Perception of Health & 1196 & & Premature baby & 1194 & \\
\hline Good & 822 & 68.73 & Yes & 171 & 14.32 \\
\hline Bad & 374 & 31.27 & No & 1023 & 85.68 \\
\hline
\end{tabular}


Table 2 Women's Postpartum-related characteristics

\begin{tabular}{|c|c|c|c|c|c|}
\hline Postpartum-related & $\mathrm{N}$ & $\%$ & Complications of partum & $\mathrm{N}$ & $\%$ \\
\hline Attended Postpartum Care & 1199 & & Severe bleeding & 1195 & \\
\hline Yes & 990 & 82.60 & Yes & 185 & 15.48 \\
\hline No & 209 & 17.40 & No & 1010 & 84.52 \\
\hline Place where received postpartum care & 989 & & Very bad smell & 1193 & \\
\hline Public hospital & 256 & 25.88 & Yes & 63 & 5.28 \\
\hline Private hospital & 188 & 19.01 & No & 1130 & 94.72 \\
\hline First level center & 526 & 53.19 & Infect surgery wounds & 1194 & \\
\hline My house & 1 & 0.10 & Yes & 94 & 7.87 \\
\hline Other place & 15 & 1.52 & No & 1100 & 92.13 \\
\hline \multirow[t]{2}{*}{ Dispensary } & 3 & 0.30 & Fainting & 1192 & \\
\hline & & & Yes & 98 & 8.22 \\
\hline Who provided postpartum care service & 1121 & & No & 1094 & 91.78 \\
\hline Doctor or doctor assistant & 843 & 75.20 & Coma & 1185 & \\
\hline Clinical assistant & 10 & 0.89 & Yes & 2 & 0.17 \\
\hline Nurse & 205 & 18.29 & No & 1183 & 99.83 \\
\hline Midwife & 4 & 0.36 & High fever & 1194 & \\
\hline Pediatric helper & 27 & 2.41 & Yes & 147 & 12.31 \\
\hline Public health worker & 19 & 1.69 & No & 1057 & 88.53 \\
\hline Other & 13 & 1.16 & Painful urination & 1190 & \\
\hline Days attended postpartum care & 965 & & Yes & 235 & 19.75 \\
\hline $0-3$ days & 213 & 22.07 & No & 955 & 80.25 \\
\hline 4-6 days & 193 & 20.00 & Pelvic pain & 1195 & \\
\hline $7-10$ days & 381 & 39.48 & Yes & 366 & 30.63 \\
\hline$>10$ days & 178 & 18.45 & No & 829 & 69.37 \\
\hline Days should attend postpartum care & 957 & & Breast infection & 1191 & \\
\hline $0-3$ days & 232 & 24.24 & Yes & 64 & 5.37 \\
\hline 4-6 days & 207 & 21.63 & No & 1127 & 94.63 \\
\hline $7-10$ days & 362 & 37.83 & Continuous urinary leak & 1189 & \\
\hline \multirow[t]{2}{*}{$>10$ days } & 156 & 16.30 & Yes & 52 & 4.37 \\
\hline & & & No & 1137 & 95.63 \\
\hline Breastfeed & 1195 & & Fecal flow & 1188 & \\
\hline Yes & 1126 & 94.23 & Yes & 3 & 0.25 \\
\hline No & 69 & 5.77 & No & 1185 & 99.75 \\
\hline
\end{tabular}

subscales when compared to their counterparts; comparison between and within these groups was statistically significant $(p<0.02)$ (Table 3). When transforming PSS to a categorical variable, Friends PSS subscale was the only subscale where the majority of women $(55.6 \%, n=$ 654 ) had higher PSS. Nonetheless, PPC attendance was strongly statistically associated $(p<0.001)$ with higher levels of PSS by subscale when evaluating the bivariate relationship. In fact, women were more likely to attend postpartum care if they had mean and higher levels of PSS Family subscale (OR: 1.9, 95\%CI: 1.4-2.7),
Significant Other subscale (OR 1.8,95\%CI: 1.3-2.4) and Total score (OR 1.8, 95\%CI:1.3-2.5) (Table 4).

Bivariate analyses for both primary variables (PPC and PSS) indicated that country of residence, age group, level of education, perception of health, health problems, intentions of pregnancy, and first-time pregnancy could potentially act as confounders (see supplemental material). In brief, postpartum care attendance was higher among women who intended their pregnancy, first-time mothers, and providing breastfeeding. As well, experiencing other health and pregnancy related complications 
Table 3 Perceived Social Support by subscale and comparison with postpartum care attendance

\begin{tabular}{|c|c|c|c|c|c|}
\hline \multicolumn{2}{|l|}{ Categories and measures } & \multicolumn{4}{|c|}{ Perceived Social Support Subscales } \\
\hline & & Family & Friends & Significant Other & Total \\
\hline Total & $\mathrm{n}$ & 1190 & 1177 & 1190 & 1134 \\
\hline Perceived Social Support Standardized T-score & Median & 46.6 & 52.3 & 46.6 & 49.9 \\
\hline \multirow[t]{2}{*}{ Perceived Social Support Categorical values } & Low - n (\%) & $675(57.6)$ & $523(44.4)$ & $613(51.5)$ & $586(51.8)$ \\
\hline & High - n (\%) & $496(42.4)$ & $654(55.6)$ & $577(47.5)$ & $546(48.2)$ \\
\hline \multirow[t]{3}{*}{ Received Postpartum Care } & $n$ & 974 & 964 & 974 & 925 \\
\hline & Mean (SD) & $50.6(9.8)$ & $50.3(10.1)$ & $50.6(9.8)$ & $50.6(9.9)$ \\
\hline & Confidence Interval & $49.9-51.2$ & $49.6-50.9$ & $49.9-51.2$ & $49.9-51.3$ \\
\hline \multirow[t]{3}{*}{ Did not receive Postpartum Care } & $\mathrm{n}$ & 206 & 203 & 206 & 199 \\
\hline & Mean (SD) & $47.1(10.5)$ & $48.4(9.5)$ & $47.1(10.5)$ & $47.1(9.9)$ \\
\hline & Confidence Interval & $45.7-48.6$ & $47.12-49.8$ & $45.7-48.6$ & $45.7-48.5$ \\
\hline \multirow[t]{2}{*}{ Mean Square } & Between groups & 1990.5 & 583.0 & 1990.5 & 1971.6 \\
\hline & Within groups & 98.6 & 99.6 & 98.6 & 98.5 \\
\hline ANOVA & $p$ & 0.001 & 0.016 & 0.001 & 0.001 \\
\hline
\end{tabular}

such as high fever was also significantly associated with postpartum care attendance in our study. Meanwhile, health conditions developed during pregnancy (gestational diabetes and hypertension) were evaluated in this study, but no significance differences were observed.

Unadjusted and adjusted models assessed the relationship between post-partum care and perceived social support, controlling for potential confounders (Table 5). The first model represents the unadjusted relationship between the PCC and Total PSS. The second model added country of residence; the third model added food insecurity, and the fourth model added educational level. The odds of attendance to postpartum care changed from $83 \%$ in the unadjusted relationship to $47 \%$ in the first multivariate model (Model 2). When controlling for two confounders (Model 3), the odds of attending postpartum care only varied $0.01 \%$. Odds of attending postpartum care were adjusted to $40 \%$ for women who had higher levels of PSS, when adding the third confounder (Model 4). In all models' higher levels of Total PSS remained statistically associated with PPC attendance $(p<0.05)$. Goodness-of-Fit statistics for all multivariate models were non-significant, indicating that the data fit the analytic models used. Women with higher levels of PSS were between 40 and 50\% more likely to attend PPC, when controlling for confounders.

Table 4 Bivariate relationship between Postpartum Care and Perceived Social Support by subscale

\begin{tabular}{|c|c|c|c|c|c|c|c|c|}
\hline \multicolumn{2}{|c|}{ Women centered variables } & \multicolumn{2}{|c|}{ Postpartum Care n (\%) } & \multirow[t]{2}{*}{ OR } & \multicolumn{2}{|c|}{ 95\% C.I. } & \multirow[t]{2}{*}{ Sig. } & \\
\hline & $\mathbf{N}$ & Yes & No & & Lower & Upper & & \\
\hline PSS Friends & 1167 & & & & & & & \\
\hline Lower than the mean & 520 & $103(50.7)$ & $417(43.3)$ & Referent & & & & \\
\hline Mean and Higher & 647 & $100(49.3)$ & $547(56.7)$ & 1.4 & 1.0 & 1.8 & 0.052 & \\
\hline PSS Significant Other & 1180 & & & & & & & \\
\hline Lower than the mean & 607 & $131(63.6)$ & $476(48.9)$ & Referent & & & & \\
\hline Mean and Higher & 573 & $75(36.4)$ & $498(51.1)$ & 1.8 & 1.3 & 2.5 & 0.001 & * \\
\hline PSS Family & 1161 & & & & & & & \\
\hline Lower than the mean & 668 & $145(70.4)$ & $523(54.8)$ & Referent & & & & \\
\hline Mean and Higher & 493 & $61(29.6)$ & $432(45.2)$ & 2.0 & 1.4 & 2.7 & 0.001 & * \\
\hline PSS Total & 1124 & & & & & & & \\
\hline Lower than the mean & 581 & $127(63.8)$ & $454(49.1)$ & Referent & & & & \\
\hline Mean and Higher & 543 & $72(36.2)$ & $471(50.9)$ & 1.8 & 1.3 & 2.5 & 0.001 & * \\
\hline
\end{tabular}


Table 5 Multivariate Models for Postpartum Care and Perceived Social Support

\begin{tabular}{|c|c|c|c|c|}
\hline & OR & \multicolumn{2}{|c|}{$95 \% \mathrm{Cl}$} & $p$-value \\
\hline \multicolumn{5}{|l|}{ Model 1. Unadjusted } \\
\hline Higher Perceived Social Support & 1.8 & 1.3 & 2.5 & 0.001 \\
\hline Lower Perceived Social Support & \multicolumn{4}{|c|}{ (Reference) } \\
\hline \multicolumn{5}{|l|}{ Model 2. Adjusted for Country } \\
\hline Higher Perceived Social Support & 1.5 & 1.1 & 2.1 & 0.023 \\
\hline Lower Perceived Social Support & \multicolumn{4}{|c|}{ (Reference) } \\
\hline \multicolumn{5}{|c|}{ Model 3. Adjusted for Country and Food Insecurity } \\
\hline Higher Perceived Social Support & 1.5 & 1.1 & 2.1 & 0.022 \\
\hline Lower Perceived Social Support & \multicolumn{4}{|c|}{ (Reference) } \\
\hline \multicolumn{5}{|c|}{ Model.4 Adjusted for Country, Food Insecurity and Education } \\
\hline Higher Perceived Social Support & 1.4 & 1.0 & 1.9 & 0.049 \\
\hline Lower Perceived Social Support & \multicolumn{4}{|c|}{ (Reference) } \\
\hline
\end{tabular}

\section{Discussion}

Latin American women's perception of social support in this study was significantly associated with post-partum care participation. PPC and PSS differ, however, by country of residence, educational level, and social factors, such as food insecurity, and further studies should use interactions and stratified analyses to further understand these confounders and related implications. PPC is a critical time that provides an opportunity to assess and enhance women's physical, social, and psychological health.

\section{Effect of health-related factors}

Postpartum women may experience pain, discomfort, and disturbances in patterns associated with physical and mental health that include changes in their body appearance, nutrition, and sleep [20,21]. These dramatic changes, adjustments, and difficulties are prompted by new demands, structural constraints, and other events in the postpartum period that can impact a woman's psychosocial wellbeing. Wiegers et al. (2006) [21] revealed that first-time parents expressed the importance of postpartum care and its role in relation to baby-care and self-care information that is provided. The relationship between breastfeeding and postpartum care in our study has also been documented in other studies reporting a strong influence of postpartum care into breastfeeding, specifically after the first 2 weeks of birth [22]. Consistent with findings in our study, maternal behavior and women's desire for more information on self-care and infant care is influenced by their perception of positive social support received [23]. Considering the social support perceived and related actions by postpartum mothers in LAC countries in our study may serve as indicative of the need for further evaluation of psychological and social factors that may change or influence actions during this vulnerable period. Another study [24] showed postpartum women linking attendance to care as an important resource for monitoring both, physical, and mental health.

Recent findings have shown that women with health conditions perceived postpartum care as essential to monitoring their health and as an intervention to prevent further complications [24]. A slightly higher attendance to postpartum care was observed in women who reported at least one health problem diagnosed by a health provider such as asthma, heart problems, cancer or high blood pressure, when compared to their counterparts. These results indicate that multidisciplinary approaches are fundamental to improve maternal health promotion strategies within health departments and health professional across LAC countries.

\section{Effect of societal-related factors}

Poor health outcomes have been associated with low educational level in several studies including quality of live and maternal health studies [25]. Specifically, in postpartum health, low educational levels have been associated with low mood in the first postpartum week [26]. Although women with higher educational attainment were more likely to attend postpartum care when compared with woman who had lower educational level in our study, the vast majority of postpartum women had a lower educational level. Concerns emerging from these results include the possibility that educational level could act as an additional predictor affecting maternal health and a possible alternative towards healthy behaviors, the refocus of educational postpartum policies is crucial.

Maternal health studies have also evaluated social factors such as food insecurity and its role during pregnancy and in the postpartum period. A strong association has been reported between food insufficiency and postpartum depression [27]. Another study revealed that this association was higher in women that have lower levels of social support [28], but the presence of instrumental social support buffers food insufficiency. Consistent results were shown in our study, women who were food insecure also exhibit lower levels of perceived social support and food insecurity decreased the probability of attending postpartum care in our study.

Our findings also suggest that postpartum care attendance may vary by country of residence. Hondurans and Costa Ricans had higher odds of postpartum care attendance when compared with Dominicans. Likewise, women from the Dominican Republic exhibit lower levels of perceived social support when compared to their counterparts and this may influence attendance to post-partum care for this subgroup. While this difference was found in our study, studies evaluating social 
support experiences in communities in Dominican Republic [29] and in Costa Rica [30], women consistently reported lower levels of social support compared to men.

These inconsistent social support and postpartum health results between countries provide insights and a baseline for approaches targeting cultural and geographically perceptions and norms. Promoting healthy pregnancies, children, and women involves a partnership that includes critical-thinking, communication, and selfassessment, with individually-targeted objectives and collective strategies between and within countries. Tangible forms of material support, such as childcare and access to transportation, should be further evaluated given that they can be common barriers to seek care and enable postpartum visit attendance.

\section{Strengths and limitations}

The parent study used a community-based, mixedmethod approach with a sample size powered to detect the differences explored in this study. The survey was validated in every community to ensure the quality of the data collected. Maternal health inferences apply only to those communities and cannot be extrapolated to the population of each country. Nevertheless, these findings common to the three countries suggest that if other communities are sampled, the results might be similar. The healthcare system and access to healthcare in each country is different, and this difference could impact attendance to PPC.

\section{Conclusion}

Social support has a direct impact on maternal role and satisfaction. Attendance to postpartum care is crucial for both a woman and her infant and other internal and external factors can play a role. Findings in this study support that to fully understand social influences on women's health during the postpartum period, we need to examine characteristics using a holistic approach from the individual to the macro system level. Moving forward in closing these gaps, future studies and approaches could include community level interventions to address perceptions and qualitative studies to understand knowledge, attitudes, beliefs and reasons associated with social support. Additionally, given that social media use played a role mediating the effect of child death in LAC countries, the contribution of these elements should be evaluated.

\section{Supplementary Information}

The online version contains supplementary material available at https://doi. org/10.1186/s41256-021-00196-1.

Additional file 1.

\section{Acknowledgements}

The authors would like to acknowledge the communities in Costa Rica, in the Dominican Republic, and in Honduras for their willingness to participate in this research study. In addition, authors would like to thank data collectors, research assistants, students, and community organizers who assisted the team. Additionally, we recognize statistical contributions from Dr. Margaret Demment, Luis D. Agosto-Arroyo, and Dr. Dongmei Li.

\section{Authors' contributions}

NRCC led this analysis and the writing of this paper; JPR contributed to the conception of this study, interpretation of findings, and contributed to this paper; ZQT contributed to the conception of this study, oversaw data collection, and contributed to this paper; SM contributed to the conception of this study, assisted with interpretation, and contributed to this paper; EA contributed to the conception of this study, oversaw data collection, and contributed to this paper; CD oversaw data collection and contributed to this paper; DJO contributed to the conception of this study and contributed to this paper; TDD oversaw the conduct of this study, contributed to study design, data collection procedures, database construction, interpretation of findings, and contributed to this paper. The author(s) read and approved the final manuscript.

\section{Funding}

This work was funded by The National Institutes of Health/Fogarty International Center Grant \#1 R25 TW 009697-01A1 and NIH National Center for Advancing Translational Sciences, "NRSA Training Core" (TL1 TR002000). The content is solely the responsibility of the authors and does not necessarily represent the official views of The National Institutes of Health of the United States.

\section{Availability of data and materials}

The datasets used and/or analyzed during the current study are available from the corresponding author on reasonable request.

\section{Declarations}

\section{Ethics approval and consent to participate}

The MundoComm project was approved by the Universidad de Ciencias Médicas (UCIMED) FWA Institutional Review Board in Costa Rica and (with local approval) in Honduras (as a proxy, since Honduras did not have an FWA Institutional Review Board). In addition, in the Dominican Republic, the study was reviewed and approved by Consejo Nacional de Bioética en Salud (CONABIOS) at the national level and the Pontificia Universidad Católica Madre y Maestra (PUCMM)'s FWA Institutional Review Board at the university level. Regulatory language for each country agency was incorporated in the survey. Additionally, the project was approved by the University of Rochester's Research Subjects Review Board. Study participants had to be able to read and verbally consent to participate. All personnel for this project completed CITI Program Training in Human Subjects Protection or the NIH's

Protección de los participantes humanos de la investigación training.

\section{Competing interests}

The authors declare that they have no competing interests.

\section{Author details}

${ }^{1}$ University of Rochester, School of Medicine and Dentistry, Obstetrics and Gynecology Department Research Division, 601 Elmwood Avenue, Rochester, NY 14642, USA. ${ }^{2}$ Pontificia Universidad Católica Madre y Maestra, Santiago De Los Caballeros 51000, República Dominicana. ${ }^{3}$ Universidad de Ciencias Médicas, 400 metros oeste del M.A.G., Carr. Vieja a Escazú, San José 10108, Costa Rica.

Received: 5 December 2020 Accepted: 24 March 2021

Published online: 07 May 2021

References

1. Langlois E, Miszkurka M, Zunzunegui M, Ghaffar A, Ziegler D, Karpd I. Inequities in postnatal care in low- and middle-income countries: a systematic review and meta-analysis. Bull World Health Organization. 2015; 93(4):259-70. https://doi.org/10.2471/BLT.14.140996. 
2. Say $L$, Raine R. Systematic review of inequalities in the use of maternal health care in developing countries: examining the scale of the problem and the importance of context. Bull World Health Organ. 2007;85(10):812-9.

3. ACOG. Optimizing Postpartum Care. 2018 OG, ed. ACOG Committee Opinion No. 736. 131: American College of Obstetricians and Gynecologists. 2018:140-150.

4. Wahn E, Nissen E. Sociodemographic background, lifestyle and psychosocial conditions of Swedish teenage mothers and their perception of health and social support during pregnancy and childbirth. Scand J Public Health. 2008; 36(4):415-23. https://doi.org/10.1177/1403494807085315.

5. Restrepo-Méndez MC, Barros AJD, Durán JRP, et al. Progress in reducing inequalities in reproductive, maternal, newborn,' and child health in Latin America and the Caribbean: an unfinished agenda. Rev Panam Salud Pública. 2015;38(1):9-16.

6. Chen C, Kuo S, Chou Y, Chen H. Postpartum Taiwanese women: their postpartum depression, social support and health-promoting lifestyle profiles. J Clin Nurs. 2007;16(8):1550-60. https://doi.org/10.1111/j.1365-2702.2 006.01837.x

7. Ngai F-W, Wai-Chi CS. Learned resourcefulness, social support, and perinatal depression in Chinese mothers. Nours Res. 2012;61(2):78-85. https://doi. org/10.1097/NNR.0b013e318240dd3f.

8. Shumaker S, Brownell A. Toward a theory of social support: closing conceptual gaps. J Soc Issues. 1984;40(4):11-36. https://doi.org/10.1111/j.154 0-4560.1984.tb01105.x.

9. Razurel C, Kaiser B, Sellenet C, Epiney M. Relation Between Perceived Stress,Social Support, and Coping Strategies and Maternal Well-Being: A Review of the Literature. Women Health. 2013;53(1):74-99. https://doi.org/1 0.1080/03630242.2012.732681.

10. House J, Umberson D, Landis K. Structures and processes of social support Annu Rev Sociol. 1988;14(1):293-318. https://doi.org/10.1146/annurev.so.14 080188.001453.

11. Ossip DJ, Avendaño E, Mclntosh S, Perez-Ramos J, David T, Demment M, et al. MundoComm: information communication technology for maternal health in Costa Rica and Latin America. Ann Global Health. 2016;82(3):595. https://doi.org/10.1016/j.aogh.2016.04.562.

12. Zimet GD, Dahlem NW, S.G. Z, Farley GK. The multidimensional scale of perceived social support. J Pers Assess. 1988;52(1):30-41. https://doi.org/1 0.1207/s15327752jpa5201_2.

13. RW B. Back-translation for cross-cultural research. Cross-Cult Psychol. 1970; 1(3):185-216. https://doi.org/10.1177/135910457000100301.

14. Mclntosh S, Perez-Ramos J, David T, et al. A globally networked hybrid approach to public health capacity training for maternal health professionals in low and middle income countries. Glob Health Res Policy. 2017;2(8).

15. Colley B, Johnson C, Morrow B, Gaffield M, Ahluwalia I. Prevalence of selected maternal and infant characteristics, pregnancy risk assessment monitoring system (PRAMS). CDC Surveill Summ. 1999;48(5):1-37.

16. CDC, MoHCDEC. Kigoma Reproductive Health Survey 2016. Tanzania. 2016

17. Andresen E, Catlin T, Wyrwich K, Jackson-Thompson J. Retest reliability of surveillance questions on health-related quality of life. J Epidemiol Community Health. 2003;57(5):339-43. https://doi.org/10.1136/jech.57.5.339.

18. Streiner DL, Norman GR, Cairney J. Health measurement scales: a practical guide to their development and use. USA: Oxford University Press; 2015.

19. Hosmer Jr DW, Lemeshow S. Applied logistic regression. Hoboken: John Wiley \& Sons, 2004.

20. Cheng C, Fowles E, Walker L. Postpartum maternal health care in the United States: a critical review. J Perinat Educ. 2006;15(3):34-42. https://doi.org/10.1 624/105812406X119002.

21. Wiegers T. Adjusting to motherhood maternity care assistance during the postpartum period: how to help new mothers cope. J Neonatal Nurs. 2006; 12(5):163-71. https://doi.org/10.1016/j.jnn.2006.07.003.

22. Postnatal IS. Care Relating to Breastfeeding. In: LV AJ, Roch S, editors. Postnatal Care. London: Palgrave; 1990. p. 18-44.

23. Hung $C$. The psychosocial consequences for primiparas and multiparas. Kaohsiung J Med Sci. 2007;23(7):352-60.

24. Henderson V, Stumbras K, Caskey R, Haider S, Rankin K, Handler A. Understanding factors associated with postpartum visit attendance and contraception choices: listening to low-income postpartum women and health care providers. Matern Child Health. 2016;20(1):132-43. https://doi. org/10.1007/s10995-016-2044-7.
25. Chimankar D, Sahoo H. Factors influencing the utilization of maternal health care services in Uttarakhand. Ethnomedicine. 2011;5(3):209-16.

26. Sebahat Atar Gürel HG. The evaluation of determinants of early postpartum low mood: the importance of parity and inter-pregnancy interval. Eur J Obstetr Gynecol Reprod Biol. 2000;91(1):21-4. https://doi.org/10.1016/S03 01-2115(99)00224-9.

27. Laraia B, Vinikoor-Imler L, Siega-Riz A. Food insecurity during pregnancy leads to stress, disordered eating, and greater postpartum weight among overweight women. Obesity. 2015;23(6):1303-11. https://doi.org/10.1002/ oby. 21075 .

28. Tsai A, Comulada S, Rotheram-Borus M. Food insufficiency, depression, and the modifying role of social support: evidence from a population-based prospective cohort of pregnant women in Peri-urban South Africa. Soc Sci Med. 2016;151:69-77. https://doi.org/10.1016/j.socscimed.2015.12.042.

29. Wallace D, Gonzalez Rodriguez $\mathrm{H}$, Walker $\mathrm{E}$, et al. Types and sources of social support among adults living with type 2 diabetes in rural communities in the Dominican Republic. Glob Public Health. 2019;14(1): 135-46. https://doi.org/10.1080/17441692.2018.1444782.

30. Schwarzer R, Gutierrez-Doña B. More spousal support for men than for women: a comparison of sources and types of support. Sex Roles. 2005; 52(7-8):523-32. https://doi.org/10.1007/s11199-005-3718-6.

\section{Ready to submit your research? Choose BMC and benefit from:}

- fast, convenient online submission

- thorough peer review by experienced researchers in your field

- rapid publication on acceptance

- support for research data, including large and complex data types

- gold Open Access which fosters wider collaboration and increased citations

- maximum visibility for your research: over $100 \mathrm{M}$ website views per year

At BMC, research is always in progress.

Learn more biomedcentral.com/submissions 